
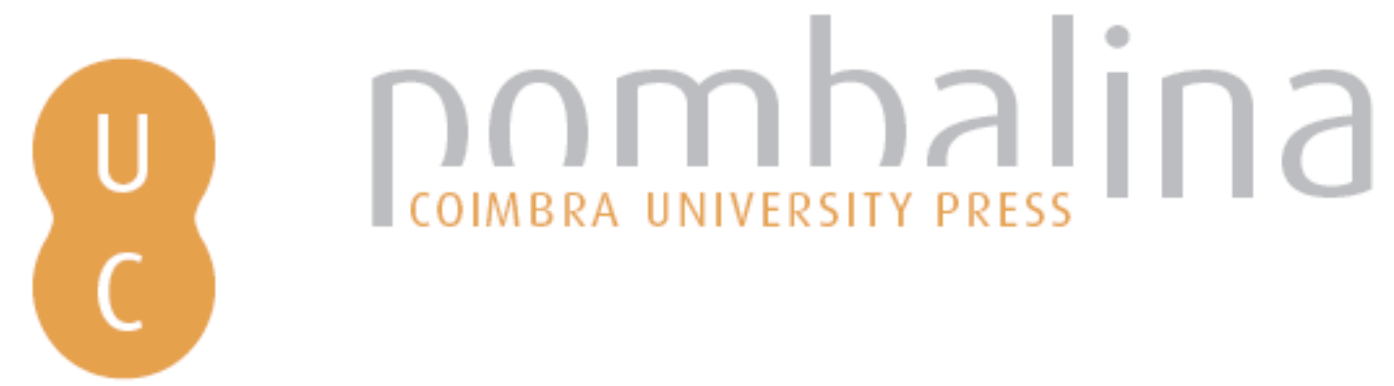

\title{
“Él y él, unidos por el amor nefando...": maternidad y travestismo en Medea es un buen chico de Luís Riaza
}

\author{
Autor(es): Ocantos, Hernán \\ Publicado por: Centro de Estudos Clássicos e Humanísticos da Universidade de \\ Coimbra; Imprensa da Universidade de Coimbra \\ URL \\ persistente: \\ URI:http://hdl.handle.net/10316.2/31721 \\ DOI: \\ DOI:http://dx.doi.org/10.14195/978-989-721-038-9_39 \\ Accessed : $\quad$ 26-Apr-2023 07:05:54
}

A navegação consulta e descarregamento dos títulos inseridos nas Bibliotecas Digitais UC Digitalis, UC Pombalina e UC Impactum, pressupõem a aceitação plena e sem reservas dos Termos e Condições de Uso destas Bibliotecas Digitais, disponíveis em https://digitalis.uc.pt/pt-pt/termos.

Conforme exposto nos referidos Termos e Condições de Uso, o descarregamento de títulos de acesso restrito requer uma licença válida de autorização devendo o utilizador aceder ao(s) documento(s) a partir de um endereço de IP da instituição detentora da supramencionada licença.

Ao utilizador é apenas permitido o descarregamento para uso pessoal, pelo que o emprego do(s) título(s) descarregado(s) para outro fim, designadamente comercial, carece de autorização do respetivo autor ou editor da obra.

Na medida em que todas as obras da UC Digitalis se encontram protegidas pelo Código do Direito de Autor e Direitos Conexos e demais legislação aplicável, toda a cópia, parcial ou total, deste documento, nos casos em que é legalmente admitida, deverá conter ou fazer-se acompanhar por este aviso.

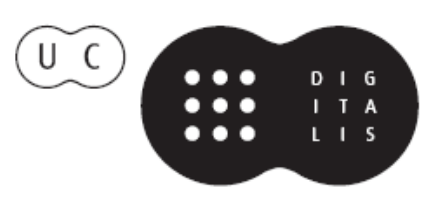




\section{De ayer a hoy}

\section{Influencias clásicas en la literatura}

\section{Aurora López, Andrés Pociña, Maria de Fátima Silva (coords.)}




\section{“ÉL Y ÉL, UNIDOS POR EL AMOR NEFANDO...": MATERNIDAD Y TRAVESTISMO EN MEDEA ES UN BUEN CHICO DE Luís Riaza}

Hernán Ocantos IES N² "Mariano Acosta"

Luís Riaza en Medea es un buen chico desanda un camino de continuidad con la tragedia euripídea. Desde la sustitución y el travestismo de sus personajes masculinos propone una serie de correspondencias dadas desde el conflicto de los límites trazados por el género y el cuerpo. La Medea griega reniega de su condición, desearía haber nacido hombre. Aquí se revela el eje que une a los personajes, el español rompe con la figura legendaria, la sustituye por un hombre aunque de alguna manera Medea ha dejado de ser mujer al cometer el filicidio.

La concepción de la obra de teatro como medio de transmisión ideológica, y no tan sólo como una actividad de estricto corte burgués y elitista, se hace patente en la dramaturgia de Riaza. Este pensamiento supone una continuación de la línea trazada por Lorca en la voz de uno de sus personajes:

"MOSQUITO (...) Yo y mi compañía venimos del teatro de los burgueses, del teatro de los condeses y de los marqueses, un teatro de oro y cristales, donde los hombres van a dormirse y las señoras... a dormirse también"'.

La ruptura y la continuidad con lo clásico van de la mano con la transgresión al sistema. El propio Riaza expresa que “... los oscuros gusanos de cada dramaturgia son los mismos y siempre procura uno librarse de ellos con los mismos exorcismos. Los de mi teatro particular puede que consistan en un ataque sañudo, terco y más o menos solapado contra todo teatro". Medea es un buen chico se encuentra enmarcada en el llamado periodo de la Transición, momento que se presenta como una especie de desierto estéril en cuanto a la composición del mapa político español, el desencanto con la democracia y la nefasta presencia de los rezagos del franquismo tales como la censura y su forma más acabada: la autocensura . Existe otro problema para que el mito filtrado por la mano labradora de Riaza se extienda por las conciencias de los españoles: la representación. $\mathrm{O}$ mejor expresado, la ausencia de la misma. ${ }^{3}$ Probablemente

\footnotetext{
${ }^{1}$ Lorca García, Federico, Los titeres de cachiporra. Tragicomedia de Don Cristóbal y la señá Rosita, Madrid, Cátedra, 1998, pp. 134-135.

${ }^{2}$ Riaza, Luís. "Pequeño paseo ante el retrato de una dama y sus perritos resplandecientes", prólogo a Retrato de dama con perrito, Madrid, Fundamentos, 1976, p. 15.

${ }^{3}$ Sólo ha sido representada en enero de 1985 en una coproducción entre el Círculo de Bellas
} 
para que su teatro realmente forme parte de un sistema revolucionario, tal como lo plantea Roland Barthes, le falte uno de los pilares que sostienen dicho sistema: llegar regularmente a un público masivo ${ }^{4}$. En este arduo contexto la función social y divulgadora del teatro se esfuma.

Las tragedias griegas han sido fundantes de las temáticas desarrolladas a lo largo del periodo contemporáneo de la literatura española en general y del teatro en particular, al tiempo que fueron utilizadas popularmente como "metáfora de la situación vivida". En su Medea es un buen chico, el español Luís Riaza traza un camino de continuidad entre sus travestidos personajes de la Nodriza y Medea y el mito de Eurípides. Esta correspondencia está presentada bajo el indudable influjo de la derrota, el hilo que enhebra ambas obras es la inocultable decepción de los protagonistas y la ineludible puesta en marcha de una serie de mecanismos de los cuales va a surgir la tragedia. Medea y Nodriza, hombres, sin hijos, enmascarados con el turbio maquillaje de la desgracia, no son capaces de engendrar para luego matar, no pueden seguir la línea filicida planteada por Eurípides. Riaza disfraza el mito. Esto explica por qué los personajes son biológicamente varones. La Medea clásica reniega de su condición de madre, ve como un castigo la posibilidad materna, para evitar este conflicto Riaza trasviste al personaje, lo sustituye, de alguna manera repara el deseo negativo de la Medea mítica ya que su Medea desea algo a lo que no puede acceder: la maternidad. Por el contrario en Eurípides el personaje reniega de su capacidad procreadora y si, tal como ha sucedido, el hecho ya está consumado sobreviene el desenlace fatal. El personaje griego desearía haber sido hombre, de modo que comparte esa suerte de travestismo con su homónimo español:

"MEDEA.- un hombre, cuando le resulta molesto vivir con los suyos, sale fuera de casa y calma el disgusto de su corazón [yendo a ver a algún amigo o compañero de edad]. Nosotras, en cambio, tenemos necesariamente que mirar a un solo ser. Dicen que vivimos en la casa una vida exenta de peligros, mientras ellos luchan con la lanza. ¡Necios! Preferiría tres veces estar a pie firme con un escudo, que dar a luz una sola vez" (Medea, versos 243-251)

Artes de Madrid y el Centro Nacional de Nuevas Tendencias Escénicas, dirigida por Luis Vera.

${ }^{4} \mathrm{El}$ semiólogo francés plantea en su artículo El teatro popular de hoy del año 1954, que para que el teatro adquiera carácter de revolucionario debe reunir tres condiciones: 1legar regularmente a un público masivo, presentar un repertorio de alta cultura y practicar una dramaturgia de vanguardia. A los efectos propone el abordaje de un repertorio clásico, en el sentido amplio del término.

${ }^{5}$ Ragué-Arias, María-José. "Del mito contra la dictadura, al mito que denuncia la violencia y la guerra”, en Foro Hispánico 27 Mitos e identidades en el teatro español contemporáneo, Amsterdam-New York, Editions Rodopi, 2005.

${ }^{6}$ Eurípides, Medea, Traducción y notas de González Medina, Alberto y López Férez, Juan 
Aquí subyace el eje que une a los personajes, Riaza quien se refiere al derrotero amoroso de Medea y Jasón como "el culmen del amor-odio/ más o menos hetero." , rompe con la figura legendaria, la sustituye por un hombre aunque de algún modo la Medea clásica pierde su condición de mujer al cometer el filicidio. Los personajes de la obra española viven dentro de esa especie de vestíbulo de sucio vodevil, no deben luchar con la lanza, deben luchar contra el muro infranqueable que supone su cuerpo y su limitación natural. Lo sustancial estriba en que la Medea euripidea puede volver a ser madre, está naturalmente dotada para ello. Los hombres, no. De todos modos la mirada del amor nefando, en el estricto sentido del término, no impide que los personajes se vean y sean vistos "como los amantes bienvistos/de dios, de sus iglesias / y de sus respetables fieles". El amor pecaminoso, el de la práctica del coito anal, nos traslada a una doble percepción del conflicto: la del arte y la de los receptores de la obra. Por un lado Medea y Nodriza simbolizan la destrucción de los prejuicios en relación con el género: aman, se desean, necesitan sentirse queridos, anhelan la maternidad/ paternidad como fin trascendente de sus opacas vidas. Por otra parte, la mirada de los otros, la de la España posfranquista y democrática, sigue funcionando como una especie de índice policíaco que imparte juicios y sentencias a esos personajes que se miran mientras esperan el dictamen moral de la sociedad. En efecto, como la "pareja de maricas no puede tener niños" (Riaza; 204) éstos serán sustituidos por perros de peluche y por la fantasía imaginaria de los personaje y del auditorio. Por momentos Nodriza parece cumplir la función de esa voz sentenciosa del afuera que se cuela en la obra, no admite a Medea ni como madre, ni como mujer:

"MEDEA.- Del niño: ¿̨a quién te parece que ha salido, a su padre o a mi? NODRIZA.- De la señora sacó el espiritu desparramado. Nada encuentro del señor en la criaturita.

MEDEA.- ;Tu resentimiento te nubla los malditos ojos!

NODRIZA.- Si la señora quiere que le confirme la paternidad del señor, sólo tiene que fijar las respuestas de su bumilde sierva..." (Riaza, 207)10

En este doble cruce de falacias, o sea, el de la ficción teatral y el de la maternidad, vislumbramos un ápice de esa voz externa. No obstante, inmediatamente Nodriza se muestra incapaz de sortear la confusión impuesta

\footnotetext{
Antonio, Madrid, Editorial Gredos, 2000, p. 82.

${ }^{7}$ Riaza, Luís. Teatro escogido. Medea es un buen chico, Madrid, Asociación de autores de teatro, 2006, p. 204.

${ }^{8}$ Ibid. 7, p. 203.

${ }^{9}$ Ibid. 7, p. 209.

${ }^{10}$ Ibid. 7, p. 208.
} 
por el mecanismo de sustitución riaciano, en particular en el episodio que la muestra en un primer contacto con su propio perrito/hijo:

"Nodriza.- (...) (Baja a sus <dominios>. Vacia una botella de leche en el cacillo y coloca éste sobre la cocina. Saca luego un perro del arcón y lo coloca sobre la mesa.) mi vientre, en este mundo!"11

En un plano simultáneo Medea se encuentra hablándole sobre el miedo a la oscuridad a su propio primogénito apócrifo. Ambos personajes ingresan al juego de roles, ambos son emboscados por sus propias trampas de identidad.

Este trayecto entrecruzado genera un acercamiento, una mímesis entre ambas obras, la clásica y la contemporánea. La idea desarrollada por Simone de Beauvoir "no se nace mujer; llega uno a serlo", luego analizada minuciosamente por Judith Butler quien pone en evidencia algunas limitaciones de la concepción de la francesa manifestando que: "Beauvoir sostiene rotundamente que una <llega a ser> mujer, pero siempre bajo la obligación cultural de hacerlo. Y es evidente que esa obligación no la crea el $\langle$ sexo . En su estudio no hay nada que asegure que la persona que se convierte en mujer sea obligatoriamente de sexo femenino"12. En efecto, Butler expresa que la teoría de la encarnación en la que se sostiene el análisis de Beauvoir se encuentra restringida por la reproducción de la distinción cartesiana entre libertad y cuerpo, y que dicha diferenciación debe replantearse en virtud de la jerarquía implícita de los géneros. La teoría queer ha ampliado el abanico de dudas y ha ofrecido una buena cantidad de respuestas a estas cuestiones. Para el caso de la obra abordada, el dilema parece recorrerse en dos sentidos. Por un lado, los personajes de un modo superficial y accesorio simulan ser mujeres, más allá de que probablemente en ese burdo remedo de la apariencia corporal se asemejen más a una caricatura del mito que al mito mismo. Esta presencia femenina en el ser interior tanto del protagonista como de su antagonista, es llevada al extremo por el autor español al proponer esa especie de metamorfosis erótica que se pone en acción cuando la maltratada Nodriza debe secar a su ama. La ocultación da paso a la aparición masculina, pues Nodriza afirma que quien juega con las uñas en el lacerado cuerpo de Medea no es ella, es Jasón, tensión que amplía el efecto de transformación: el hombre que se erige en mujer y que accede a actuar como hombre. Los límites se difuminan, se disuelven, se amalgaman en el juego corporal. Pero la disyuntiva no se cierra tan sólo en el plano corporal, la angustia devenida de la soledad, fruto de la

\footnotetext{
${ }^{11}$ Ibid. 7, p. 208.

${ }^{12}$ Butler, Judith, El género en disputa, Barcelona, Paidós, 2007, p. 57.
} 
opresión ejercida por ese monstruo del afuera mencionado en la nana que se canta al inicio, se expresa en el plano de la interioridad en las elocuentes palabras de Nodriza:

"MEDEA.- Yyo, nodriza, ¿̇te amo?

NODRIZA.-La niña sólo se ama a símisma, pero no es correspondida debidamente... »3

Por otra parte, y de aquí el conflicto con el género, los personajes no pueden ingresar al mundo femenino debido al límite impuesto por su cuerpo, tienen pene, no pueden engendrar, no pueden parir $y$, por consiguiente, no pueden matar. La toma de conciencia de la limitación, es decir de su verdadera fisonomía, los subleva:

"MEDEA.- Algún día te daré de vergajazos, nodriza...

NODRIZA.- Llegado el momento, pondré mi culo a disposición de la verga de madame... (Besa el culo a MEDEA.)

MEDEA.- ¡Aparta tus hocicos de mí! ;Me llenas de ambigüedades!'”14

Tal como expresa Beatriz Preciado en su propuesta de contrasexualidad ${ }^{15}$, los personajes no dejan de ser un producto del contrato social heterocentrado cuyas performatividades normativas se hallan impresas en sus cuerpos como verdades naturales. La rebelión ante este producto será factible el día que se libere o se desprivatice o se resexualice el ano, en este sentido el fragmento citado ut supra resulta premonitorio. Además tal como se mencionó en las líneas precedentes, los personajes se hallan inmersos en un ambiente ganado por el tufo de la derrota, las ambigüedades son las que no les permiten imponerse ni siquiera en el plano del juego simbólico: se trata de personajes andróginos que no podrán sortear ese destino. Los dos aspectos que dan título al presente trabajo se encuentran en el momento culminante del texto riaciano, cuando el proceso de desmitificación del mito ya ha sido puesto en marcha: Medea debe consumar el asesinato de su hijo/perrito al tiempo que se reconoce en ese mundo estéril y masculino:

"MEDEA. - Falta la última baza de la partida sin bordes que se juega entre Jasón y yo... (Acaricia al perro que se encuentra en la cama.) Y la baza eres tú hijo mio; el rastro más profundo que Medea deja de su paso por este mundo desabrido y ácido..."

${ }^{13}$ Ibid. 7, pp. 213-214.

${ }^{14}$ Ibid. 7, p. 217.

${ }_{15}$ Preciado, Beatriz, Manifiesiesto contra-sexual, Madrid, Editorial Ópera prima, 2002, pp. 18-19. 
Inmediatamente la alusión a Jasón y al afuera amenazante:

“(...) Ya regresas de tu vivir en el ajeno afuera, tú, Jasón (...) Ya regresas después de haber esparcido tu esperma de la perpetuación...”

Y luego, al fin, la confesión, el reconocimiento de su propio ser, el de su incapacidad reglada por la convención del sexo:

"...Después de haber traicionado al pobre y estéril invertido, al triste marica que Medea es... (Coge al perro en los brazos.) Pero no, estéril no... Conmigo tuviste bijos no enviados por las divinidades preñadoras... (Besa al perro.) Tú fuiste el hijo de la imaginación, capaz de vencer al dios embutidor de vida hasta la repetición y el estrago y la náusea... Tú fuiste el hijo del hombre Jasón y del hombre Medea, y no del dios que dispusiera que el hombre naciera del preceptivo vientre de la mujer"16.

Recordemos que durante la España franquista y opresiva tanto los movimientos como el debate sobre la liberación sexual se encontraban en la clandestinidad. En la inmediata Transición estas voces van a exigir urgentes reivindicaciones más allá de las dificultades de la consumación de un movimiento sólido ${ }^{17}$. La clandestinidad de los personajes no puede correrse del ámbito cerrado propuesto por el autor español, ni Medea ni Nodriza escaparán del cerco impuesto por el monstruo amenazante del afuera.

Como sostiene Steiner ${ }^{18}$ el hombre es ennoblecido por el rencor vengativo o la injusticia de los dioses y esto no lo vuelve inocente, lo purifica como si hubiera pasado por las llamas. Riaza invoca a esos dioses y subvierte la tradición mítica desde la treta del artificio, desde la tergiversación del género, su protagonista no puede ser purificada por los dioses:

"MEDEA.- Echa agua en el baño.

NODRIZA.- No bañaremos, a pesar de todo, a la señora. No procede durante las horas profanas.

MEDEA.- La purificación no será la de Medea. Trae el agua y marcha a descansar." ${ }^{\text {99 }}$

El agua solamente traerá el aliciente de la muerte simbólica de su hijo/ perro.

${ }^{16}$ Ibid. 7, p. 240.

${ }^{17}$ Las divergencias internas llevará a que los grupos de lesbianas se unan a las feministas heterosexuales en procura de obtener el derecho del divorcio, la contracepción y el aborto; por otra parte los gays se promulgarán en función de una ley estatal para derogar la homofobia.

${ }^{18}$ Steiner, George, La muerte de la tragedia, Caracas, Monte Ávila Latinoamericana, 1991

${ }^{19}$ Ibid. 7, p. 239. 
Queda claro que las denominadas minorías de antaño siguen manteniendo esa indigna posición dentro de las consideraciones de las sociedades contemporáneas, incluso más allá de concretos avances en materia legislativa. Toda la gama de los subgrupos que conforman este grupo mayor sigue padeciendo esta segregación, por caso los transexuales y los travestis siguen relegados a acatar el magro destino trágico que los está aguardando a la salida de su clóset interior: sus puestos de comando están delimitados por la prostitución y la pornografía. En este aspecto Riaza sí se muestra un paso al frente de todas las posiciones y teorías: el mito le permite atizar el fuego de la conciencia, aunque más no sea para acercarse mínimamente al dilema de la identidad de esas minorías obligadas a la ocultación. La pieza nos permite acercarnos a este significativo tema mediante el grito acallado de los infaustos personajes y su representación en la sociedad española de aquellos tiempos.

En la obra de Eurípides, luego de cometer sus asesinatos e inmediatamente después de que el Corifeo anuncia el suceso a Jasón, Medea expresa que el dolor la libera y responsabiliza por la muerte de los niños a su esposo. Una vez más las tragedias se ligan, si atendemos a los vaivenes del género y del cuerpo puestos de relieve por el poeta griego al regalarle el centro de la escena a la mujer, a Medea. 


\section{Bibliografía}

Barthes, Roland, Escritos sobre teatro, Barcelona, Paidós, 2009.

Bertens, Hans, Literary theory. The Basics, Londres, Routledge, 2007.

Boring Zatlin, Boring, "Theatre in Madrid: The difficult transition to democracy", Theatre Journal, 32, Nº (Dec. 1980).

Butler, Judith, El género en disputa, Barcelona, Paidós, 2007.

- Deshacer el género, Barcelona, Paidós, 2006.

"Sex and gender in Simone de Beauvoir's Second sex", en Yale French Studies, N772, Simone de Beauvoir: Witness a century, (1986).

Cantó Sabuco, Assumpta, "La Teoría Queer: características y consecuencias en el estado español", en Teoria Queer: de la transgresión a la transformación social, Fundación Centro de Estudios Andaluces, 2009.

García Lorca, Federico, Los titeres de cachiporra. Tragicomedia de Don Cristóbal y la señá Rosita, Madrid, Cátedra, 1998.

Oliva, César, Teatro español del Siglo XX, Madrid, Síntesis, 2004.

Preciado, Beatriz. Manifiesto contra-sexual, Madrid, Editorial Ópera prima, 2002.

—_ Testo yonqui, Madrid, Espasa Calpe, 2008.

Ragué-Arias, Maria-Josep. "Del mito contra la dictadura, al mito que denuncia la violencia y la guerra”, en Foro Hispánico 27 Mitos e identidades en el teatro español contemporáneo, Amsterdam-New York, Editions Rodopi, 2005.

Riaza, Luís, Teatro escogido. Medea es un buen chico, Madrid, Asociación de autores de teatro, 2006.

"Pequeño paseo ante el retrato de una dama y sus perritos resplandecientes", prólogo a Retrato de dama con perrito, Madrid, Fundamentos, 1976.

Ruiz Pérez, Pedro, "Teatro y metateatro en la dramaturgia de Luís Riaza”, en Anales de Literatura española, Universidad de Alicante, 1993. 